\title{
Two Cases of Continuous Fetal Heart Rate Monitoring in Twins
}

\author{
P. J. STEER, R. W. BEARD
}

British Medical fournal, 1973, 3, 263-265

\section{Summary}

This report describes two cases of twin pregnancy in which continuous heart rate monitoring of both twins was successfully carried out during labour. In both cases monitoring permitted early diagnosis of fetal distress and both mothers were delivered by caesarean section. Continuous fetal heart rate monitoring permits diagnosis of fetal distress in the second twin much earlier than conventional methods.

\section{Introduction}

The case for intensive fetal monitoring in labour is now well established, and in many departments it is regarded as mandatory-particularly in "at risk" patients. Normally this is done by continuous fetal heart rate recording supplemented by fetal blood sample $\mathrm{pH}$ determination.

Monitoring the second twin has been hampered by the impossibility of obtaining a fetal blood sample and until recently by difficulty in detecting the fetal heart. Recording the fetal heart rate of the second twin by intermittent auscultation with the fetal stethoscope has always been of doubtful value because of the difficulty of distinguishing between the heart sounds of the two fetuses. Caesarean section for fetal distress in the second twin has already become accepted practice based on heart rate and on the passage of meconium, but only after delivery of the first twin (Gerber et al., 1969). Now that external monitoring of the fetal heart rate is possible with ultrasound, the condition of both fetuses can be followed throughout labour with much more confidence than before.

The following two cases show how knowledge of the condition of the second twin from the continuous fetal heart rate pattern can prove decisive in the management of labour.

\section{Case 1}

An Italian woman aged 22, para $0+0$, had a twin pregnancy, both fetuses being cephalic presentations. The antenatal period was uneventful.

Spontaneous onset of labour occurred two days before term when vaginal examination showed dilatation of the cervix to be $3 \mathrm{~cm}$, and artificial rupture of the membranes released meconium-stained liquor. The mean $\mathrm{pH}$ of a fetal scalp blood sample from the first twin was 7.31. A scalp clip was applied to the first twin and an ultrasonic transducer placed on the mother's abdomen over the second twin. A continuous record of heart rate was obtained on separate cardiotocographs (Hewlett Packard 8020A).

The mother's uterus was contracting efficiently and 45 minutes later she required sedation with $150 \mathrm{mg}$ of pethidine and $50 \mathrm{mg}$ of promethazine hydrochloride intramuscularly. Both fetal heart traces were normal (fig. 1), that of the first twin remained so throughout.

Obstetric Unit, St. Mary's Hospital, London W2 1PG

P. J. STEER, M.B., B.S., Postregistration House Officer

R. W. BEARD, M.D., F.R.C.O.G., Professor of Obstetrics

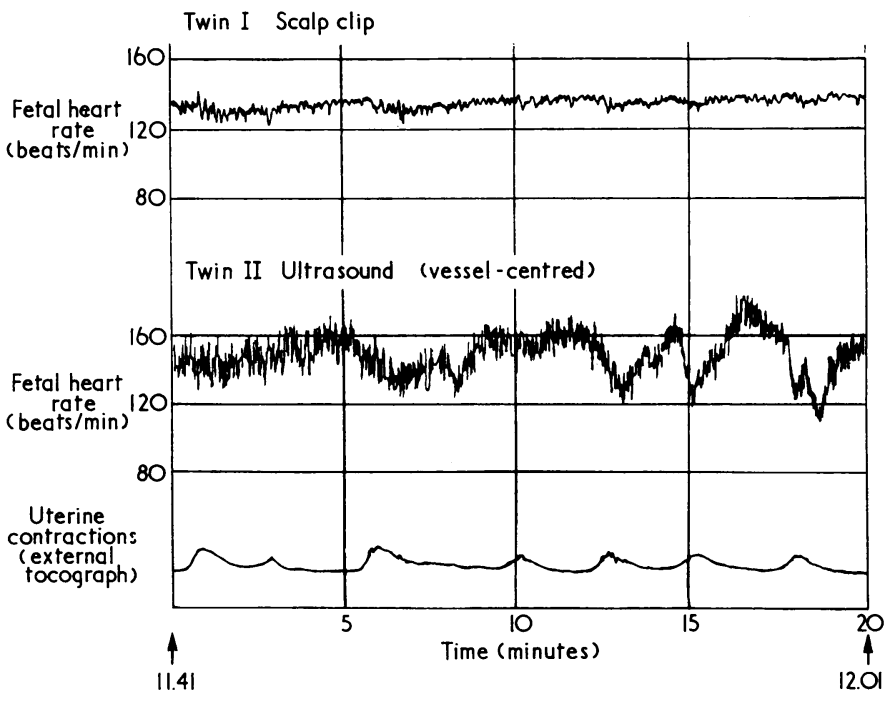

FIG. 1-Case 1. Normal fetal heart traces in twins.

One hour and forty-five minutes after admission the fetal heart trace of the second twin began to show deep late decelerations (fig. 2) indicating fetal distress, at which time a vaginal examination revealed dilatation of the cervix to be $4 \mathrm{~cm}$.

A lower segment caesarean section was carried out 45 minutes later on the grounds of fetal distress in the second twin. At operation the first twin was a male in good condition though it looked pale, and it cried at one minute. Mean venous cord blood $\mathrm{pH}$ was $7 \cdot 21$ and the baby's weight was $2,900 \mathrm{~g}$.

The second sac was ruptured and thick meconium staining of the liquor found. This baby, also male, was severely asphyxiated, plethoric, wasted, hypotonic, and "small for dates" in appearance. It weighed $2,300 \mathrm{~g}$. Its ventilations were irregular at $64 / \mathrm{min}$. It required

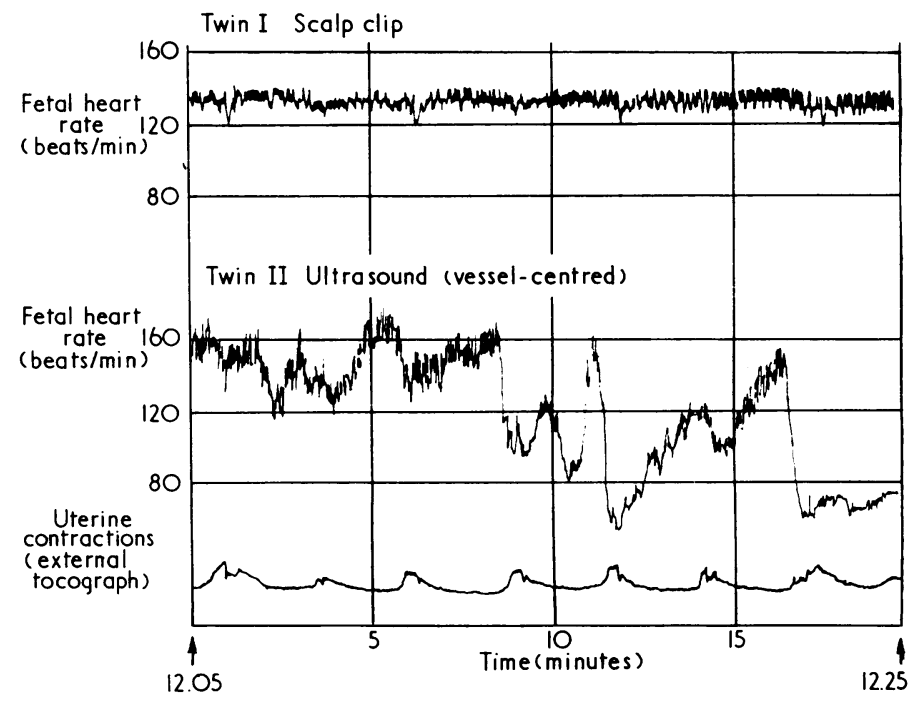

FIG. 2-Case 1. Indications of fetal distress in second twin. 
intubation and intermittent positive pressure ventilation for 45 minutes before spontaneous ventilation occurred. Mean venous cord blood $\mathrm{pH}$ was $7 \cdot 19$. Mean maternal venous blood $\mathrm{pH}$ was $7 \cdot 28$.

At first it was difficult to understand why the mean venous cord blood $\mathrm{pH}$ of the second twin was not lower in the presence of such severe clinical asphyxia.

However, macroscopic examination of the placentas showed a single chorion. In addition, their placentas overlapped and shared about $25 \%$ of their total area. Vessels from each cord could be seen to anastomose and there was clearly a joint circulation. In only a very few cases have vascular anastomoses been found in dizygotic twin placentas (giving rise to human blood chimeras) and a joint circulation to the degree noted in this case is virtually diagnostic of identical twins (Morison, 1970). (Final confirmation of monozygosity would require complicated serology or fingerprinting and measurement of other physical parameters after the age of 2 years.)

It was suspected that via the joint circulation the first twin had been buffering the second, so that the cord blood $\mathrm{pH}$ did not reflect its true tissue acidosis. This would also explain why the first twin was in such good condition despite a relatively low blood $\mathrm{pH}$.

In addition to mixing of blood it became evident that a large transfusion of blood must have occurred from twin one to twin two, because from initially similar cord blood haemoglobin values consistent with mixing, twin one became anaemic and twin two became polycythaemic (see table). In order to correct its blood loss (which was apparent from its pallor) twin one had to expand its circulating volume with a resulting drop in haemoglobin concentration. Conversely twin two had to reduce its excessive blood volume (it was noted to look plethoric) by excretion of fluid component, producing a rise in haemoglobin concentration.

Haemoglobin Values in Twins in Case 1

\begin{tabular}{|c|c|c|c|c|c|c|c|}
\hline & & & & & & \multicolumn{2}{|c|}{ Cord Blood Values $(\mathrm{g} / 100 \mathrm{ml})$} \\
\hline & & & & & & Twin One & Twin Two \\
\hline $\begin{array}{l}\text { Day of delivery } \\
\text { Second day } \\
\text { Third day }\end{array}$ & $\because$. & $\begin{array}{l}\ldots \\
\cdots\end{array}$ & $\begin{array}{l}\cdots \\
\cdots\end{array}$ & $\begin{array}{l}\cdots \\
\cdots\end{array}$ & $\begin{array}{l}. \\
\because .\end{array}$ & $\begin{array}{l}19 \cdot 3 \\
14 \cdot 2\end{array}$ & $\begin{array}{l}22 \cdot 7 \\
25 \cdot 1\end{array}$ \\
\hline
\end{tabular}

Though the blood donor in cases of twin transfusion is usually the smaller and growth-retarded baby (due to continuing blood loss in utero) in the series of 19 cases of twin transfusion described by Rausen et al. (1965) in two out of the four cases in which the circulation was sufficiently balanced for both twins to survive the donor twin had the greater birth weight. In both these cases the donor was also born first. It may be that the dynamics of labour can cause an acute reversal of the "normal" direction of blood flow across the anastomosis, and that the sudden development of cardiac embarrassment in twin two as shown by the fetal heart trace (fig. 2) was due to heart failure resulting from hypervolaemia.

The rapidity of this process, together with accompanying peripheral circulatory failure and hence greatly reduced tissue perfusion, would also be factors in the development of severe tissue acidosis without a large drop in cord blood $\mathrm{pH}$.

Twin two was given $5 \mathrm{ml}$ of $8.4 \%$ sodium bicarbonate and $5 \mathrm{ml}$ of $5 \%$ dextrose intravenously to correct its acidosis. Despite this, two and a half hours later a blood sample from an umbilical catheter showed that the blood $\mathrm{pH}$ had fallen to $7 \cdot 15$, the $\mathrm{PCO}_{2}$ was $19 \mathrm{~mm} \mathrm{Hg}$, the $\mathrm{Po}_{2}$ was $235 \mathrm{~mm} \mathrm{Hg}$, and the bicarbonate was $6 \mathrm{mEq} / \mathrm{l}$. These results were evidence of the true extent of the tissue acidosis that existed once the buffering effect of twin one had been removed. A further $8 \mathrm{ml}$ of $8.4 \%$ sodium bicarbonate were required to correct the acidosis completely, and five hours later the $\mathrm{pH}$ was $7 \cdot 31$, the $\mathrm{PcO}_{2}$ $31 \mathrm{~mm} \mathrm{Hg}$, the $\mathrm{Po}_{2} 62 \mathrm{~mm} \mathrm{Hg}$, and the bicarbonate $30 \mathrm{mEq} / \mathrm{l}$.

Further maintenance by intravenous fluids was necessary for three days. On the second postoperative day the baby became hypotonic and irritable. The blood sugar was found to be $30 \mathrm{mg} / 100 \mathrm{ml}$ and the calcium $7 \mathrm{mg} / 100 \mathrm{ml}$. It was treated with phenobarbitone $5 \mathrm{mg}$ three times a day and $10 \mathrm{ml}$ of $10 \%$ calcium gluconate three-hourly. These were discontinued after four days. The baby then made steady progress and its condition was considered to be normal by the 14th postoperative day.

The first twin was always well and at no time in the neonatal period did it show any evidence of intrapartum asphyxia.

Mother and both babies were discharged well on the 15th postoperative day.

\section{Case 2}

A 24-year-old Rhodesian African, para $0+0$, had a twin pregnancy, both fetuses being cephalic presentations. The antenatal period was uneventful.

Spontaneous onset of labour occurred at 38 weeks' gestation, at which time vaginal examination showed cervical dilatation to be $3 \mathrm{~cm}$, and artificial rupture of the membranes released meconiumstained liquor. The mean $\mathrm{pH}$ of a fetal scalp blood sample (twin one) was 7.31 and a scalp clip was applied to this twin. An ultrasonic transducer was placed on the mother's abdomen over the second twin and a continuous reading of heart rate from both twins was recorded on separate cardiotocographs. An epidural anaesthetic was then administered.

Eight hours later the contractions had fallen off to one in 10 minutes, the trace of twin one showed loss of beat to beat variation and late decelerations (fig. 3). A fetal scalp blood sample showed a mean $\mathrm{pH}$ of $7 \cdot 40$. The fetal heart trace of the second twin was normal and the cervix was $3 \frac{1}{2} \mathrm{~cm}$ dilated.

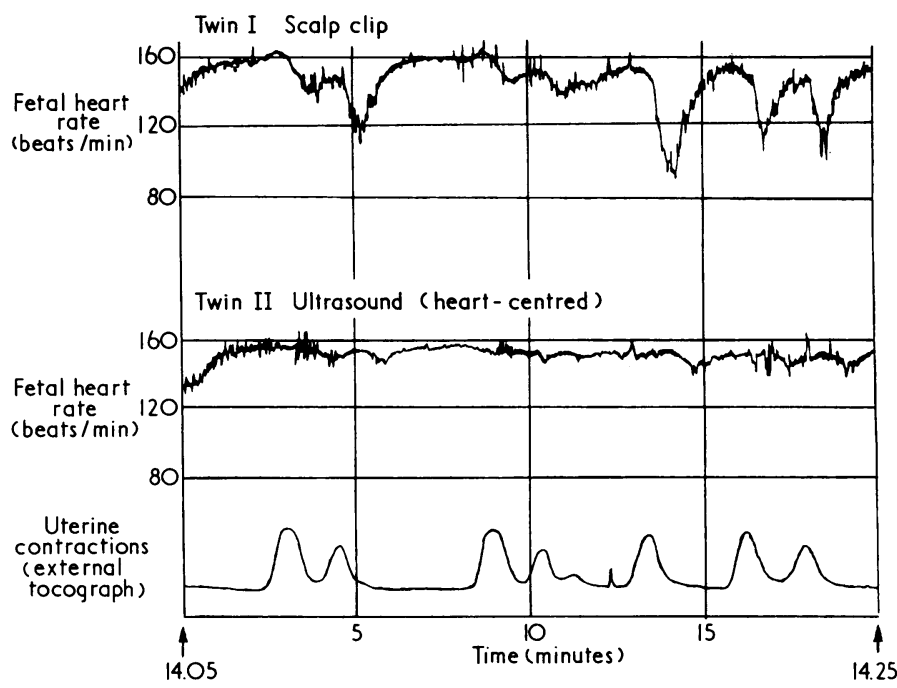

FIG. 3-Case 2. Fetal heart traces in twins showing loss of beat to beat variation and late deceleration in first twin.

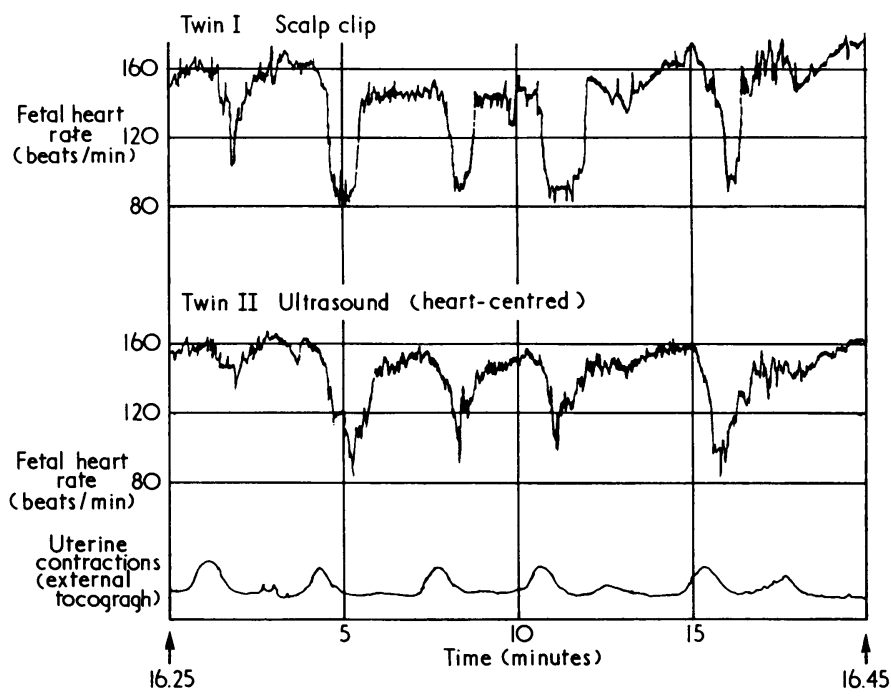

FIG. 4-Case 2. Late deceleration-more frequent in first twin, and beginning in second twin.

Two and a half hours later the trace of twin one showed more frequent late decelerations with a prolonged lag time. The cervix was only $4 \mathrm{~cm}$ dilated and further fetal scalp blood sampling showed a 
mean $\mathrm{pH}$ of $7 \cdot 15$. At the same time the trace of twin two began to show late decelerations (fig. 4).

Thirty minutes later a lower segment caesarean section was carried out. At delivery the first twin had a mean venous cord blood pH of 7.09 and a heart rate of 50 beats/min. After intubation with intermittent positive pressure ventilation for two minutes the baby responded well, and the Apgar score at five minutes was nine. It was a female and weighed $2,130 \mathrm{~g}$.

The second twin was transverse and was also in poor condition at birth with a mean venous cord blood $\mathrm{pH}$ of $7 \cdot 10$. It responded well to intubation and intermittent positive pressure ventilation and recovered in two minutes. It was also female and weighed $2,210 \mathrm{~g}$. The placenta was monochorionic to macroscopic examination and the twins were therefore likely to be identical. There was no evidence of joint placental circulation. The maternal venous blood $\mathrm{pH}$ at the time of section was $7 \cdot 36$.

Both babies were kept in the special care baby unit for 36 hours and made good progress. Mother and babies were discharged home well on the 13th postoperative day.

\section{Discussion}

These cases illustrate the advantages of monitoring both fetuses in labour. In the first case only continuous fetal heart rate monitoring would have given early enough indication of rapidly developing distress in the second twin to save it by caesarean section.

In the second case, though caesarean section was primarily for the first twin, it was evident that the second twin was also unlikely to withstand the stress of delivery, particularly with the inevitable delay after delivery of the first.

\section{References}

Gerber, J. A., Choithani, H., and O'Leary, J. A. (1969). Obstetrics and Gynecology, 33, 770 .

Morison, J. E. (1970). In Foetal and Neonatal Pathology, 3rd edn., p. 184. London, Butterworths.

Rausen, A. R., Seki, M., and Strauss, L. (1965). Fournal of Pediatrics, 66, 613

\title{
End of the Trend? A I2-year Study of Age at Menarche
}

\author{
T. C. DANN, D. F. ROBERTS
}

British Medical Fournal, 1973, 3, 265-267

\section{Summary}

A 12-year study of menarchial age in all girls entering the University College of Swansea (1959-70) suggests that the downward trend in age at menarche has ceased in Britain. The turning point appears to have occurred in girls born about 1946.

\section{Introduction}

By the mid-1950s it was established that in girls in Britain, as elsewhere in Europe, menarche had been occurring at steadily earlier ages over the past 100 years. The rate of this secular diminution in age of menarche was calculated to be about three to four months per decade (Tanner, 1955). The continuation of this trend was shown by Tanner (1962, 1965) with critical documentation, and various factors responsible for it were identified. It seemed to us to be highly unlikely that this diminution would continue indefinitely and therefore that it would be of interest to keep a check on menarchial age in an attempt to detect the first signs of any slackening of the trend in Britain. While to do this thoroughly would necessitate a large scale investigation, we felt that it would be useful nonetheless to initiate a small sample inquiry. In 1959 we therefore started to collect information on all girls entering the University College of Swansea in each year. The material accumulated to date thus consists of recall data from a succession of cross-sectional surveys relating to one particular section of the population.

\section{Subjects and Methods}

In the medical examinations carried out on all girls at the time of their admission to the University College of Swansea

\section{University of Warwick, Coventry}

T. C. DANN, M.A., M.D., D.OBST.R.C.O.G., Medical Officer

University of Newcastle upon Tyne, Newcastle upon Tyne, NE2 4AA D. F. ROBERTS, M.A., D.PHIL., Reader in Human Genetics from 1959 onwards the age at menarche was recorded. The 1970 intake was the last to be included in this study, and, with the exception of the 1963 intake for which this item was omitted, the data are continuous over 12 years. Each girl was asked when her menarche had occurred. Such recall data are notoriously liable to error or bias from a variety of sources, summarized for example by Roberts and Dann (1967). They depend on recollection accuracy, intelligence of the girl, composition of the sample in terms of age and pubertal status, and the clarity of definition of the event. Such errors are thought to be minimal in the present data, for the sample relates to girls above average in intelligence and reliability of memory, all questioned between the ages of 18 and 21. There was no girl who had not attained menarche at the time of examination. Most of the girls were quite clear in recalling the quarter or the actual month, though the data were recorded as age at birthday preceding menarche for ease of analysis. The few girls whose answers indicated that they themselves were in some doubt were excluded from the analysis. Other relevant details were also noted on the total of over 2,400 girls and the following variables were incorporated in the analysis: menarchial age in years, recorded as age at birthday preceding; year of birth; the number of siblings the girl has, and her numerical position in her sibship; the father's occupation described numerically as in the Registrar General's classification.

\section{Results}

The data for the first seven years (intakes of 1959-65) were analysed and published (Roberts and Dann, 1967; Dann and Roberts, 1969). This first analysis showed a clear and progressive diminution in menarchial age which was highly significant. Its rate was compatible with that calculated by Tanner (1965) from European studies over the last century and from American studies since the beginning of the 20th century. Effects were also shown of family size, position in family, and physique of the girl. Later menarche tended to occur in girls from larger families, of later position in sibship, and of more linear physique. But clearly there was no evidence in that first analysis suggesting cessation of the secular trend. 